\title{
Factors Influencing Crude Oil Biodegradation by Yarrowia lipolytica
}

\author{
Tatiana Felix Ferreira*, Maria Alice Zarur Coelho and Maria Helena Miguez da Rocha- \\ Leão \\ Departamento de Engenharia Bioquímica; Universidade Federal do Rio de Janeiro; 21941-909; Rio de Janeiro - \\ RJ - Brasil
}

\begin{abstract}
Yarrowia lipolytica is unique strictly aerobic yeast with the ability to efficiently degrade hydrophobic substrates such as n-alkenes, fatty acids, glycerol and oils. In the present work, a $2^{4}$ full factorial design was used to investigate the influence of the independent variables of temperature, agitation, initial cell concentration and initial petroleum concentration on crude oil biodegradation. The results showed that all variables studied had significant effects on the biodegradation process. Temperature, agitation speed and initial cell concentration had positive effects, and initial petroleum concentration had a negative effect. Among the crude oil removal conditions studied, the best temperature and agitation conditions were $28^{\circ} \mathrm{C}$ and $250 \mathrm{rpm}$, respectively.
\end{abstract}

Key words: Yarrowia lipolytica, crude oil, biodegradation

\section{INTRODUCTION}

Many marine oil spills occur every year. On several occasions, major oil spills have contaminated marine shorelines, causing severe localized ecological damage to near-shore communities (Atlas 1995).

Among the methods used to remediate oilcontaminated environments, bioremediation has been widely used. This method uses the enzymatic capability of microorganisms to degrade petroleum hydrocarbons (Ron and Rosenberg 2002). Some microorganisms degrade alkanes (normal, branched and cyclic paraffins), others aromatics, and others both paraffinic and aromatic hydrocarbons (Atlas 1995). Bioremediation is an internationally approved technology for the costeffective clean-up of oil-contaminated sites. These technologies involve enhancing the natural

\footnotetext{
*Author for correspondence: tatianafelix@ufrj.br
}

biological transformation of chemical- or petroleum-derived contaminants into less toxic and/or less mobile forms (Abdulsalam and Omale 2009). These technologies are receiving increased attention due to their low cost and effectiveness (Vidali 2001).

The biodegradation of petroleum in marine environments is carried out largely by diverse bacterial populations. However, in the present work a yeast strain isolated from tropical estuarine water in Rio de Janeiro (Brazil), Yarrowia lipolytica IMUFRJ 50862, was used.

Yarrowia lipolytica is a unique strictly aerobic yeast with the ability to produce a wide spectrum of products, such as organic acids and extracellular enzymes (Amaral et al. 2006). Y. lipolytica is one of the most extensively studied "nonconventional" yeasts and is currently used as model for the study of protein secretion, peroxisome biogenesis, dimorphism, degradation 
of hydrophobic substrates, and several new fields (Fickers et al. 2005). Given its ability to utilize hydrophobic substrates such as alkanes, fatty acids and oil, $Y$. lipolytica strains are emerging as very promising agents for the treatment of both mineral oil pollution and plant oil waste (Scioli and Vollaro 1997; Kim et al. 1999; Felice et al. 2004). There are many factors that influence the bioremediation process and should be monitored. These factors include temperature, type and concentration of the pollutant(s), nutrient and oxygen availabilities and the concentration of microorganisms in the impacted site. Therefore, some environmental conditions must be adjusted, for example, by improving aeration and correcting the moisture level and $\mathrm{pH}$, to stimulate bioremediation (Baptista et al. 2005).

The goal of the present research was to investigate the influence of several factors on crude oil biodegradation by Yarrowia lipolytica IMUFRJ 50682. The factors analyzed were temperature, agitation speed, initial oil concentration and inoculum concentration.

\section{MATERIALS AND METHODS}

\section{Microorganism}

A wild-type strain of Yarrowia lipolytica (IMUFRJ 50682) was isolated from an estuary in the vicinity of Rio de Janeiro, Brazil (Haegler and Mendonça-Haegler 1981), and identified by the Microbiology Institute of Federal University of Rio de Janeiro. The strain was conserved at $4{ }^{\circ} \mathrm{C}$ on YPD-agar medium containing (w/v) yeast extract $(1 \%)$, peptone $(2 \%)$, glucose $(2 \%)$ and $\operatorname{agar}(3 \%)$.

\section{Materials}

Peptone and yeast extract were obtained from Oxoid, glucose was obtained from Reagen, and agar and chloroform were obtained from Vetec.

The crude oil used was Marlim petroleum provided by PETROBRAS and was characterized as heavy oil $\left(19^{\circ} \mathrm{API}\right)$. The seawater was obtained from Espírito Santo Bay, Brazil.

\section{Culture conditions}

For cell proliferation, $Y$. lipolytica was inoculated into YPD medium (1\% yeast extract, $2 \%$ peptone and $2 \%$ glucose) at $28{ }^{\circ} \mathrm{C}$ for 48 hours. Cells were centrifuged, washed with distillated water and transferred to $125 \mathrm{~mL}$ Erlenmeyer flasks containing $50 \mathrm{~mL}$ of medium (seawater and petroleum). The Erlenmeyer flasks were incubated on a rotary shaker for 120 hours. Samples were taken daily to monitor cell growth. The remaining crude oil was analyzed at the end of each experiment. In parallel, control experiments were performed to analyze the oil lost by evaporation and sampling. The petroleum concentration, cell concentration, temperature and agitation speed were varied according to experimental design described below.

\section{Experimental design}

To study the influence of some factors on the crude oil biodegradation process by $Y$. lipolytica, a $2^{4}$ full factorial design with 8 axial points and 3 central points was implemented using Statistica 7.0. The independent variables studied were temperature, agitation speed, initial cell concentration and initial oil concentration. The values shown in Table 1 represent the limits for each factor analyzed. The dependent variable used was the percentage of oil removed.

Table 1 - Experimental range and levels of the independent variables analyzed in the $2^{4}$ full factorial design.

\begin{tabular}{cccccc}
\hline Independent Variables & \multicolumn{5}{c}{ Levels } \\
\cline { 2 - 6 } & -2 & -1 & 0 & +1 & +2 \\
\hline Temperature $\left({ }^{\circ} \mathrm{C}\right)$ & 20 & 24 & 28 & 32 & 36 \\
Agitation $(\mathrm{rpm})$ & 70 & 115 & 160 & 205 & 250 \\
Petroleum $(\% \mathrm{v} / \mathrm{v})$ & 0.1 & 1.0 & 2.0 & 3.0 & 4.0 \\
Inoculum $(\mathrm{mg} / \mathrm{mL})$ & 0.10 & 0.55 & 1.00 & 1.45 & 1.90 \\
\hline
\end{tabular}

\section{Analytical Methods}

Cell Growth

Cell growth was followed using optical density measurements at $570 \mathrm{~nm}$; these values were converted into $\mathrm{mg} / \mathrm{ml}$ using a previously established factor. This method provided only qualitative results because only the optical density of the aqueous phase was measured even though some of cells migrated into the organic phase. 
Determination of Crude Oil degradation

An oil phase extraction was performed with $25 \mathrm{~mL}$ of chloroform at the end of each crude oil degradation test. After that, the solution of crude oil extracted was diluted and analyzed in a spectrophotometer (DR4000UV (HACH)) at 240 $\mathrm{nm}$. The Marlim petroleum spectrum exhibits an intense absorption at this wavelength. However, it is important to note that this method for crude oil quantification is not the best way to quantify the total oil concentration because only a few aromatic hydrocarbons absorb at $240 \mathrm{~nm}$. This measure gives us only an approximate value of the removal level.

\section{RESULTS AND DISCUSSION}

The experimental design results are presented in Table 2. Under the conditions tested, the oil removal percentage ranged from 12 to $90 \%$. The results of the central points (experiments 25, 26 and 27) were very similar, showing that the bioprocess was reproducible. It is also important to note that the difference between maximum and minimum values of the response variable $(78 \%)$ is much greater than the variation observed for the central point $(4 \%)$, confirming that the variation in the removal values are due to the changes in the bioremediation conditions.

Table 2 - Experimental design and results of the $2^{4}$ full factorial design.

\begin{tabular}{cccccc}
\hline Experiments & Temperature $\left({ }^{\circ} \mathbf{C}\right)$ & Agitation $(\mathbf{r p m})$ & Petroleum $(\boldsymbol{\%} \mathbf{v} / \mathbf{v})$ & Inoculum $(\mathbf{m g} / \mathbf{m L})$ & \% Removal \\
\hline 1 & 24 & 115 & 1.0 & 0.55 & 37 \\
2 & 32 & 115 & 1.0 & 0.55 & 41 \\
3 & 24 & 205 & 1.0 & 0.55 & 42 \\
4 & 32 & 205 & 1.0 & 0.55 & 45 \\
5 & 24 & 115 & 3.0 & 0.55 & 16 \\
6 & 32 & 115 & 3.0 & 0.55 & 19 \\
7 & 24 & 205 & 3.0 & 0.55 & 20 \\
8 & 32 & 205 & 3.0 & 0.55 & 23 \\
9 & 24 & 115 & 1.0 & 1.45 & 62 \\
10 & 32 & 115 & 1.0 & 1.45 & 65 \\
11 & 24 & 205 & 1.0 & 1.45 & 65 \\
12 & 32 & 205 & 1.0 & 1.45 & 69 \\
13 & 24 & 115 & 3.0 & 1.45 & 32 \\
14 & 32 & 115 & 3.0 & 1.45 & 35 \\
15 & 24 & 205 & 3.0 & 1.45 & 35 \\
16 & 32 & 205 & 3.0 & 1.45 & 38 \\
17 & 20 & 160 & 2.0 & 1.00 & 21 \\
18 & 36 & 160 & 2.0 & 1.00 & 31 \\
19 & 28 & 70 & 2.0 & 1.00 & 35 \\
20 & 28 & 250 & 2.0 & 1.00 & 52 \\
21 & 28 & 160 & 0.1 & 1.00 & 90 \\
22 & 28 & 160 & 4.0 & 1.00 & 22 \\
23 & 28 & 160 & 2.0 & 0.10 & 12 \\
24 & 28 & 160 & 2.0 & 1.90 & 71 \\
25 & 28 & 160 & 2.0 & 1.00 & 41 \\
26 & 28 & 160 & 2.0 & 1.00 & 37 \\
27 & 28 & 160 & 2.0 & 1.00 & 39 \\
\hline
\end{tabular}

The highest oil removal percentage $(90 \%)$ was obtained in experiment 21 , in which the oil concentration was maintained at level -2 (inferior axial point), followed by experiment 24 (71\%), in which the inoculum concentration was maintained at level +2 (superior axial point). Consequently, the experiments that combined an oil concentration at the inferior level (-1) with an inoculum concentration at the superior level $(+1)$ (experiments 9, 10, 11 and 12) resulted in a higher crude oil removal percentage.

Figure 1 shows the Pareto chart obtained using the experimental design, calculated using different types of interactions between variables. The initial 
oil concentration (3) had the greatest effect on the dependent variable $(\alpha=95 \%)$, followed by the inoculum concentration (4). Increases in the initial oil concentration have a negative effect on oil removal, and increases in the inoculum concentration have a positive effect. The agitation speed (2) and temperature (1) also had significant positive effects on oil removal. In addition, two other parameters were statistically significant - the quadratic terms for the initial oil concentration and the temperature, the first of which had a positive effect, and the second of which had a negative effect. The quadratic terms for agitation speed and inoculum concentration and the interaction terms for oil/inoculum concentration, agitation/inoculum concentration, agitation/oil concentration, temperature/oil concentration, temperature /inoculum concentration and temperature/agitation had no significant effects on oil removal $(\alpha=95$ $\%)$.

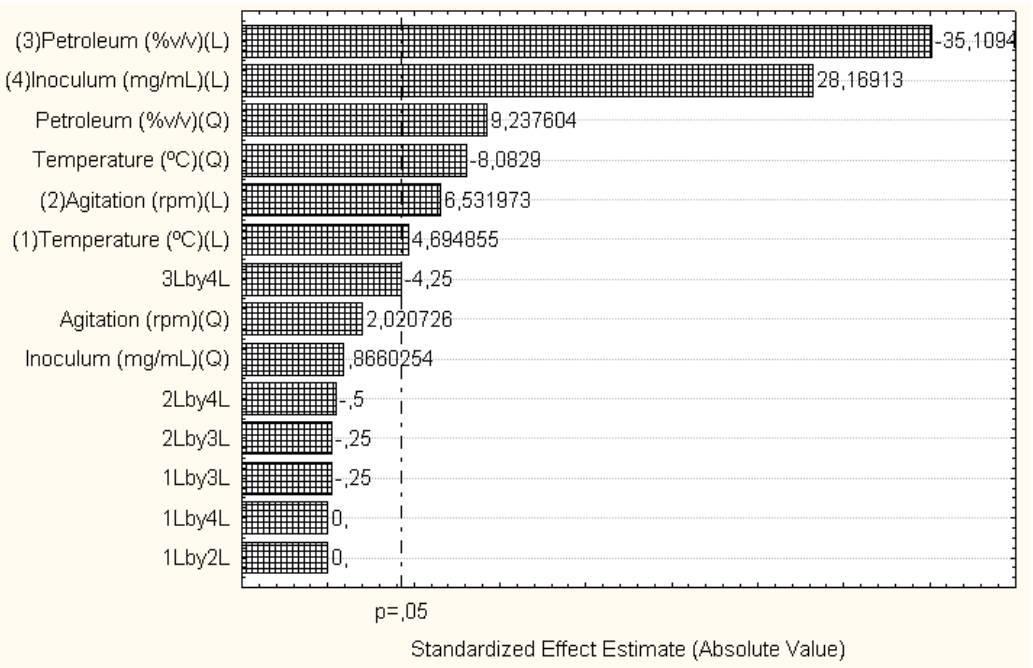

Figure 1 - Pareto chart of the standardized effects for oil removal obtained using the $2^{4}$ full factorial design.

Some studies have reported a negative effect of the initial oil concentration on crude oil removal. Del'Arco and França (2001) used a mixed culture of landfarming associated with indigenous microorganisms in the bioremediation of sandy sediments contaminated with light Arabian oil and observed different rates of removal after 29 days (33.7, 32.9 and $28.9 \%$ oil and fats; 88.5, 35.3 and $13.0 \%$ n-alkanes $\mathrm{C}_{14}-\mathrm{C}_{26} ; 100,61.3$ and $59.4 \%$ pristane) for different initial oil concentrations (14 $\mathrm{g} / \mathrm{kg}, \quad 12 \mathrm{~g} / \mathrm{kg}$ and $28 \mathrm{~g} / \mathrm{kg}$, respectively), corroborating the results obtained in this work. These results show that some compounds in Marlim petroleum can be toxic to $Y$. lipolytica IMUFRJ 50682 above a certain concentration, inhibiting the metabolism of the microorganism.

Previous publications have also reported the positive effect of the inoculum concentration, agitation speed and temperature. The positive effect of the inoculum concentration showed that $Y$. lipolytica IMUFRJ 50682 is able to consume the Marlim petroleum hydrocarbons despite this oil being heavy. This petroleum has a high density $\left(18,93{ }^{\circ} \mathrm{API}\right)$, contains $3.1 \%$ asphaltenes, has a resin-to-asphaltene ratio of 8.1 , has a saturated-toaromatic ratio of 1.6, and contains $2.66 \% \mathrm{~N}, \mathrm{~S}$ and $\mathrm{O}$. Based on these characteristics, this oil is characterized as non-biodegradable. A higher microbial population results in a greater oil biodegradation rate, especially under the conditions that were used for the experiment, that is, without the addition of nutrients to support microbial growth. Therefore, the inoculum amount has an important role.

Studies report the degradation of alkanes such as polycyclic aromatic hydrocarbons (PAHs) under anoxic conditions, but the anaerobic degradation rate of hydrocarbons is often less than the equivalent aerobic degradation rate (Head and Swannell, 1999). Grishchenkov et al. (2000) isolated bacteria strains from petroleumcontaminated soil and observed the degradation of $20-25 \%$ of the total amount of oil under aerobic conditions in 10 days, but under anaerobic 
conditions, the same strains took 50 days to degrade $15-18 \%$ of the total petroleum present. The strain used in this work is strictly aerobic, and therefore the aeration of the system is important to promote the hydrocarbon oxidation by the microorganism. The positive effect of agitation shows that the maximum oxygen saturation was not achieved in the range of agitation studied. Greater system agitation promotes increased aeration, contributing to oil removal, but after the maximum oxygen saturation level is reached, further increases in agitation do not improve oil removal because the aeration rate will not change. The positive effect of temperature on oil removal can be explained by increases in the hydrocarbon solubility and the enzymatic activity of microorganisms, which ultimately contribute to increases in the biodegradation rate. However, above $40{ }^{\circ} \mathrm{C}$, the membrane becomes more susceptible to hydrocarbon toxicity (Leahy and Collwell, 1990), which explains the negative effect of the quadratic term for temperature. Moreover, a very high increase in temperature causes a reduction in microorganism enzymatic activity and therefore reduces the hydrocarbon biodegradation rate.

The positive effect of the quadratic term for the initial oil concentration can be explained by the levels used for this variable (Table 1). The quadratic term is generated by the axial points, which differed greatly $(0.1$ and $4.0 \% \mathrm{v} / \mathrm{v})$ : level +2 was 40 times higher than level -2 . However, the oil removal in experiment 21 (level -2) was only approximately 4 times greater than that in experiment 22 (level +2 ) (Table 2), giving the impression that a very large increase in the initial oil concentration would have a positive influence on oil removal. In fact, in experiment 21 complete oil removal should have occurred because the compounds easily assimilated by the yeast were quickly consumed during the initial days of the experiment, leaving $10 \%$ recalcitrant compounds. In experiment 22, the strain was able to remove 20 $\%$ of the oil in 120 hours; this percentage corresponds to compounds that are easily consumed by $Y$. lipolytica.

Table 3 presents the variance analysis (ANOVA). The ANOVA shows a high $\mathrm{R}(0.96$, correlation coefficient) and a good performance for the regression $F$ test (calculated value was approximately 35 times the listed value). It was adjusted using a second order model. The factors that were not statistically significant were eliminated from the model and added to the lack of fit except for the interaction between the oil concentration and the inoculum concentration. Because this variable is in the marginal region $(0.1$ $<p>0.05)$, it was not removed from the model.

As the model exhibited a good fit, it was possible to analyze the response surface. The model obtained to describe the response surface of oil removal by $Y$. lipolytica IMUFRJ 50682 is expressed in Equation 1.

$$
\begin{aligned}
& \% \operatorname{Re} \text { moval }=40,67+1,92 \times \text { temperature }-3,81 \times \text { temperature }^{2}+2,67 \times \text { agitation }^{-14,33 \times} \times \\
& {[\text { petroleum }]+3,68 \times[\text { petroleum }]^{2}+11,50 \times[\text { inoculum }]-2,12 \times[\text { petroleum }] \times[\text { inoculum }]}
\end{aligned}
$$

$\underline{\text { Table } 3 \text { - Analysis of variance (ANOVA) for oil removal as the response. }}$

\begin{tabular}{ccccc}
\hline Source of variation & Sum of squares & Degrees of freedom & Mean squares & \multirow{2}{*}{ test } \\
\hline Regression & 9335.9 & 7 & 1333.70 & 88.98 \\
Residual & 284.8 & 19 & 14.99 & \\
Lack of fit & 276.8 & 17 & 16.28 & \\
Pure error & 8.0 & 2 & 4.00 & \\
Total & 9620.7 & 26 & 370.03 & \\
\hline
\end{tabular}

$\mathrm{F}_{0,95 ; 7 ; 19}=2.54 ; \mathrm{R}=0.96$.

Figure 2 (A) shows the response surface, which allows the optimization of the conditions of temperature and agitation speed for oil removal.
An oil concentration at level $-1(1 \% \mathrm{v} / \mathrm{v})$ and an inoculum concentration at level $+1(1.45 \mathrm{mg} / \mathrm{mL})$ were fixed in this response surface. 
(A)

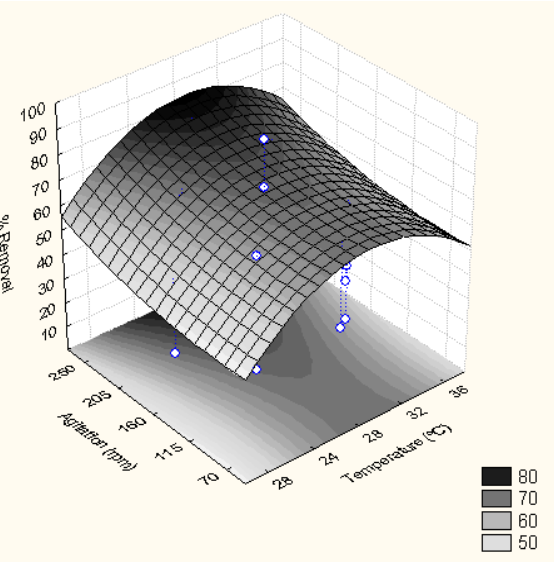

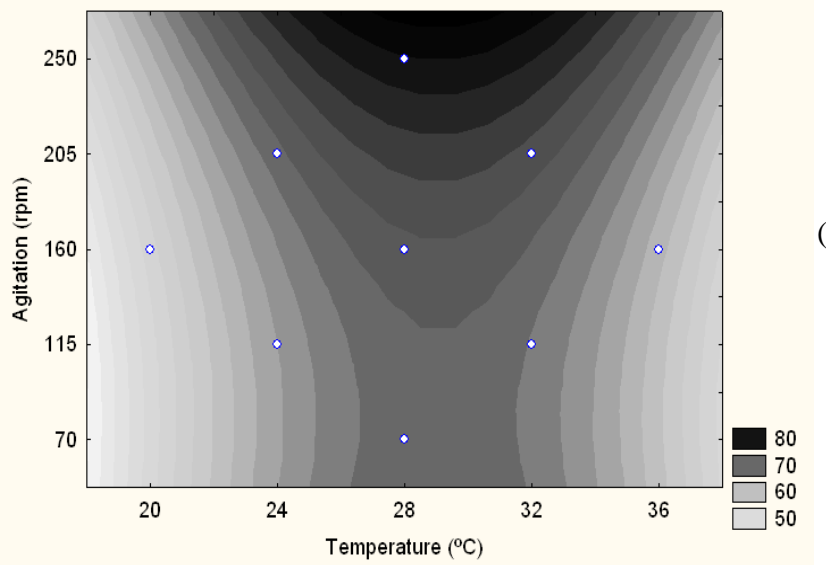

(B)

Figure 2 - Response surface (A) and contour lines (B) for oil removal as function of agitation and temperature.

It can be observed that the highest oil removal occurred when the temperature was close to the central point $\left(28^{\circ} \mathrm{C}\right)$ and when the agitation speed was near the maximum level $(250 \mathrm{rpm})$. This result is clearly shown by the contour lines in Figure 2 (B).

However, the extrapolation of the variable temperature (axial points) results in a decrease in oil removal, indicating that $28{ }^{\circ} \mathrm{C}$ is the optimum temperature for oil removal. However, the same does not occur for agitation. As this variable increases to the upper limit (250 rpm), an increase in removal is observed. Therefore, it is not possible to prove that $250 \mathrm{rpm}$ is the best agitation speed because the effects of agitation speeds greater than $250 \mathrm{rpm}$ are not known. However, it is known that there will be an agitation speed at which the aeration will be maximal. Above that point, the amount of oil removed may not be affected by increases in the agitation speed because the oxygen transfer rate is at the maximum value, thus limiting hydrocarbon biodegradation.

The $2^{4}$ central composite rotational design (DCCR) allowed us to study the effects of the independent variables temperature, agitation speed, inoculum concentration and initial oil concentration on crude oil removal. All variables had significant influences on oil removal, with temperature, agitation speed and inoculum concentration having positive effects and initial oil concentration having a negative effect.

Among the bioremediation conditions studies, the best conditions were a temperature and agitation speed of $28{ }^{\circ} \mathrm{C}$ and $250 \mathrm{rpm}$, respectively.
However, it is not possible to characterize these conditions as optimal conditions because no experiment using an agitation greater than $250 \mathrm{rpm}$ was performed to determine if a greater agitation speed would increase oil removal.

\section{ACKNOWLEDGMENTS}

The Authors acknowledge Agência Nacional do Petróleo, Gás Natural e Biocombustíveis (ANP) (PRH-13) and Conselho Nacional de Desenvolvimento Científico e Tecnológico (CNPq).

\section{REFERENCES}

Abdulsalam S, Omale AB. Comparison of biostimulation and bioaugmentation techniques for the remediation of used motor oil contaminated soil. Braz. Arch. Biol. Technol.. 2009; 52 (3): 747-754.

Amaral PFF, Lehocky M, Barros-Timmons AMV, Rocha-Leão MHM, Coelho MAZ, Coutinho JAP. Cell surface characterization of Yarrowia lipolytica IMUFRJ 50682. Yeast. 2006; 23: 867-877.

Atlas RM. Petroleum biodegradation and oil spill bioremediation. Mar. Pollut. Bull.. 1995; 31: 178182.

Baptista SJ, Cammarota MC, Freire DDC. Production of $\mathrm{CO}_{2}$ in crude oil bioremediation in clay soil. Braz. Arch. Biol. Technol.. 2005; 48: 249-255.

Felice BD; Pontecorvo G, Cargagna M. Degradation of waste waters from olive oil mills by Yarrowia lipolytica ATCC 20255 and Pseudomonas putida. Acta Biotechnologica. 2004; 17(3): 231-239. 
Fickers P, Benetti PH, Wache Y, Marty A, Mauersberger S, Smit MS, Nicaud JM. Hydrophobic substrate utilisation by the yeast Yarrowia lipolytica and its potential applications. FEMS Yeast Res. 2005; 5: 527-543.

Grischenkov VG, Townsend RT, McDonald T J, Autenrieth RL, Bonner JS, Boronin A M. Degradação of petroleum hydrocarbons by facultative anaerobic bacteria under aerobic and anaerobic conditions. Process Biochem. 2000; 35(9): 889-896.

Haegler AN, Mendonça-Haegler LC. Yeast from marine and astuarine waters with different levels of pollution in the State of Rio de Janeiro, Brazil. Appl. Environ. Microbiol. 1981; 41(1): 173-178.

Head IM, Swannell RPJ. Biorremediation of petroleum hydrocarbon contaminants in marine habitats. Curr. Opin. Biotechnol. 1999; 10: 234-239.

Kim TH, Lee JH, Oh YS, Bae KS, Kim SJ. Identification and Characterization of an Oildegrading Yeast, Yarrowia lipolytica 180. J. Microbiol. 1999; 37(3): 128-135.
Leahy JG, Colwell RR. Microbial Degradation of Hydrocarbons in the Environment. Microbiol. Rev. 1990; 54(3): 305-315.

Ron EZ, Rosenberg E. Biosurfactants and oil bioremediation. Curr. Opin.Biotechnol. 2002; 13: 249-252.

Scioli C, Vollaro L. The use of Yarrowia lipolytica to reduce pollution in olive mill wastewaters. Water Research. 1997; 31(10):2520-2524.

Vidali M. Bioremediation: An overview. J. Appl. Chem. 2001; 73(7): 1163-1172.

Received: September 16, 2011; Revised: March 9, 2012; Accepted: July 19, 2012. 


\section{Página Em}

Branco 